\title{
Weather Data for Building Simulation: Grid Resolution for Climate Zone Delineation
}

\author{
Renjith Jayapalan Nair ${ }^{1}$, Eleonora Brembilla ${ }^{1}$, Christina Hopfe ${ }^{1}$, John Mardaljevic ${ }^{1}$ \\ ${ }^{1}$ Loughborough University, Loughborough, United Kingdom
}

\begin{abstract}
Classification of climate zones for building design and energy assessment purposes plays a vital role in aiding building engineers and architects in achieving energy efficiency in buildings using building performance simulation. Previous studies highlighted the need for climate assessments at higher resolutions for the purpose of climate classification but failed to infer the resolution requirement. In this study, climate zones of Kerala (one of the 29 States in India) are defined and delineated with climate data from grid resolutions of 10, 15, 20 and $25 \mathrm{~km}$. The delineated zones are then assessed by comparing them with the thermal performance of a building representative of building typology of Kerala to identify the grid resolution necessary for zone delineation.
\end{abstract}

\section{Introduction}

The International Energy Agency (IEA) estimates that, of the total housing stock that would exist in India by 2030, only one-fourth has been built as of 2015 with the rest yet to be constructed (IEA, 2015). This is in marked contrast to developed regions such as Europe and the US. The energy use in the residential building sector in India is expected to undergo a drastic change with an anticipated rise in energy use of about $65 \%$ to $75 \%$ of 2005 levels by 2050 (van Ruijven et al., 2011). Thus, performance evaluation of proposed designs becomes an increasingly important consideration. Classification of climate zones for building design and energy assessment purposes plays a vital role in aiding building engineers and architects in achieving energy efficiency in buildings (Walsh et al., 2017).

The National Building Code (NBC) of India classifies the country for building design purposes into five major climatic zones (BIS, 2016). The classification is based on the study conducted by Ali et al. (1993) in which mean monthly maximum temperature and humidity data from 225 stations were used to delineate the zones.

The ASHRAE climate zone classification method classifies the country into different zones based on heating and cooling degree days and precipitation. The climate zones in India were defined with data from a combination of ground station data (51 stations) and remote sensing data (Standard 169, 2013). A number of studies (Bansal and Minke, 1995; Singh et al., 2007; Pawar et al., 2015) investigated the climate data in different magnitudes to classify and delineate the climate in India into different zones. Though these studies highlighted the need for location-specific climate assessments, the grid resolution required to delineate climate zones was not inferred.

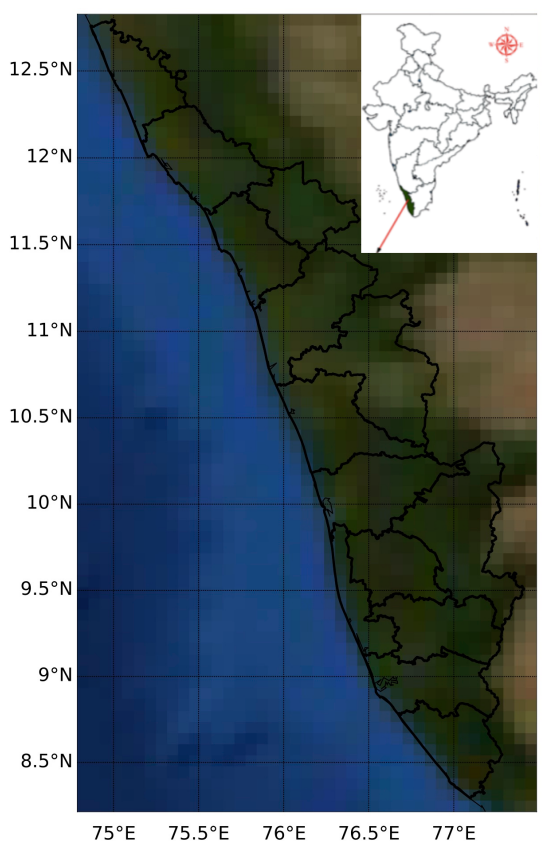

Figure 1: Location of Kerala with respect to the other 28 States of India.

This study aims to identify the appropriate grid resolution required to classify and delineate climate zones for building design and performance assessment. The study focuses on the State of Kerala (Figure 1) which is one of the 29 States in India, located in the South Western part of the country between the Arabian Sea (West) and mountain ranges - Western Ghats (East). 
As part of the Government's vision to provide housing for all, a project titled "Livelihood Inclusion and Financial Empowerment (LIFE) mission" is being implemented in Kerala. Under this project, the Government of Kerala plans to build more than 750,000 houses (Issac, 2018). The beneficiaries (i.e. the people of the State) are free to choose among 12 proposed designs which will be used for the construction of the building irrespective of the location or climate.

The existing climate zone classification methods classify Kerala under a single climate zone. The NBC of India classifies Kerala as a Warm-Humid climate zone (BIS, 2016) while the ASHRAE climate zone classification identifies Kerala as belonging to Extremely Hot Humid climate zone (Standard 169, 2013).

A previous study examined climate data across the 14 main cities in Kerala and identified the existence of locations with different climate characteristics (Jayapalan Nair et al., 2018). The results of the study resonated in the Government's Post Disaster Needs Assessment report (GoK, 2018) which highlighted the urgent need for amendments in Kerala's building codes to account for the local climatic variations in building designs.

The present study forms part of a larger project that aims to develop a methodology to assist early building design stages in terms of energy and environmental performance, and that is specifically tailored, in the first instance, for the State of Kerala.

\section{Methods}

The aim of the present study is to define the grid resolution needed for the classification and delineation of climatic zones. The first part of this section describes the methods adopted to define the climate zones. Subsequent parts of the section describe the methods carried out to examine the appropriateness of different grid resolutions in delineating climate zones.

\section{Climate zone definition}

The NBC 2016 (BIS, 2016) adopted the adaptive thermal comfort model based on the "Indian Model for Adaptive Comfort (IMAC)" developed by Manu et al. (2016) for the design of natural and mixedmode ventilated buildings. The present study used a method based on the IMAC model related to mixedmode ventilated buildings (Equation 1) to analyse the climate data for locations across Kerala and define the climate zones. The comfort acceptability limits were calculated using the equation developed by Manu et al. (2016):

$$
T_{c}=0.28 T_{o}+17.9
$$

where $\mathrm{T}_{c}$ is the neutral or comfort temperature in degree Celsius, $\mathrm{T}_{o}$ is the 30 -day outdoor running mean air temperature ranging from $13^{\circ} \mathrm{C}$ to $38.5^{\circ} \mathrm{C}$. The limits of $90 \%$ acceptability are $\pm 3.5^{\circ} \mathrm{C}$.
All the hours in a year were classified into Hours Requiring Heating $(\mathrm{HRH})$ and Hours Requiring Cooling (HRC). HRH is defined as the hours at which the value of hourly outdoor dry bulb temperature goes below the IMAC lower acceptability limit $\left(T_{c}-3.5^{\circ} \mathrm{C}\right)$ and HRC is defined as the hours at which the value of hourly outdoor dry bulb temperature goes above the IMAC upper acceptability limit $\left(T_{c}+3.5^{\circ} \mathrm{C}\right)$. The limits were calculated using Equation 1.

$\mathrm{HRH}$ and HRC values are calculated based on the value of hourly outdoor dry bulb temperatures with respect to the IMAC acceptability limits. This is an idealised case where no thermal envelope is considered. The actual HRH and HRC values for a building will depend on the thermal envelope characteristics.

Standardised typical meteorological years were available only for a limited number of places in Kerala. Thus, the study had to resort to weather files derived from the Meteonorm software (Remund et al., 2014). Percentages of HRH and HRC were calculated for locations spaced at $25 \mathrm{~km}$ grid across Kerala based on Indian Model of Adaptive Comfort (IMAC). With altitude being a major factor influencing $\mathrm{HRH}$ and $\mathrm{HRC}$, the inflection point for $\mathrm{HRH}$-Altitude curve (B1) and HRC-Altitude curve (B2) were calculated using piecewise regression analysis (Marsh and Cormier, 2001). These points (B1 and B2) were then used to define the regions into three different adaptive climate zones:

1. Adaptively Hot Zone (AHZ): regions with altitude lower than B1 where the building thermal performance is characterised by cooling demand.

2. Adaptively Mixed Zone (AMZ): regions with altitude between B1 and B2 where the building thermal performance is characterised by heating and cooling demand.

3. Adaptively Cold Zone (ACZ): regions with altitude greater than B2 where the building thermal performance is characterised by heating demand.

\section{Climate zone delineation}

To determine the appropriate grid resolution required for delineating climate zones, grids of 10, 15, 20 and $25 \mathrm{~km}$ spacings were considered. The highest grid resolution used was $10 \mathrm{~km}$. This was because, in Meteonorm, weather files are derived based on the distance of the location from the nearest ground station in Meteonorm's database. The Meteonorm database contains a total of 8275 weather stations and 5 geostationary satellites (Remund et al., 2014). Satellite data is used to derive the weather files when measured radiation data is not available from stations within 200 $\mathrm{km}$ from the location of interest. The satellite images (at resolutions of 2 to $3 \mathrm{~km}$ for Europe and $8 \mathrm{~km}$ for rest of the world) are processed for daily means of global radiation and then summed up to get monthly 
values.

The altitude values for each of the grid points for the 10, 15, 20 and $25 \mathrm{~km}$ spacings were collected and climate zones of Kerala were delineated over these grids separately.

Since the climate zones were defined and delineated for building design and performance assessment purposes, a building representative of building typology of Kerala was modelled and its thermal performance across the State at the highest grid resolution considered (i.e. $10 \mathrm{~km}$ ) was used to determine the spacing requirement. The building geometry and specifications used in the study are identical to the one used by Jayapalan Nair et al. (2018).

The building modelled has gross floor dimensions of $5.45 \mathrm{~m} \mathrm{x} 6.90 \mathrm{~m}$ and a floor to ceiling height of $2.9 \mathrm{~m}$. The building has windows (single glazed with a window to wall ratio of $20 \%$ ) on all four facades. The floor of the building lies at an elevation of $0.45 \mathrm{~m}$ above ground level and is made of dense concrete. The walls are constructed of brick with plastering on both sides. The roof construction is reinforced cement concrete.

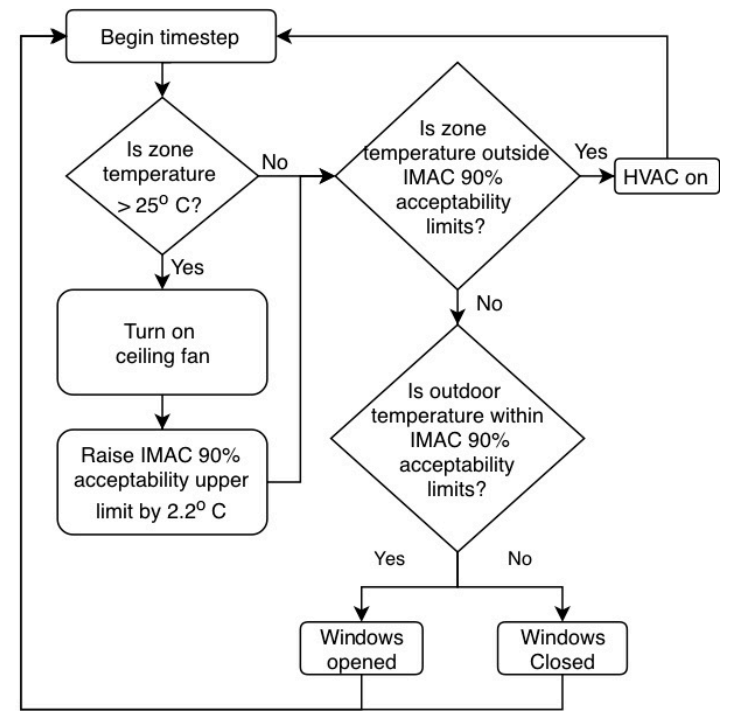

Figure 2: Window and ceiling fan operation.

The building was modelled to have mixed mode ventilation with windows and ceiling fans being operated as shown in Figure 2. The introduction of ceiling fans is the only change made with respect to the model used by Jayapalan Nair et al. (2018). The use of ceiling fans is considered as one of the main mechanisms in Warm-Humid climates to improve the indoor thermal comfort (Manu et al., 2014; Nicol, 1974; Cheng and $\mathrm{Ng}, 2006$ ). The heating and cooling set points were based on the IMAC adaptive thermal comfort model. When ceiling fans were in operation the cooling set point (i.e. IMAC $90 \%$ acceptability upper limit) was offset by $2.2^{\circ} \mathrm{C}$ (Standard 55,2013 ).
The total energy demand for heating and cooling for the building at $10 \mathrm{~km}$ grid locations across Kerala was assessed by carrying out dynamic thermal simulations in EnergyPlus. Jayapalan Nair et al. (2018) identified three cities in Kerala that had different climatic characteristics. Consequently, in this study, regions around these cities were investigated in detail, with respect to the building's thermal performance variation, to assess the appropriateness of zone delineation for the different grid resolutions considered.

\section{Results}

\section{Climate zone definition}

To define the climate zones in Kerala, HRH and HRC values for the locations spaced at $25 \mathrm{~km}$ grids were calculated. The points of inflection were identified using piecewise regression analysis. Figure 3 shows the variation of $\mathrm{HRH}$ and $\mathrm{HRC}$ against altitude. The point of inflection for HRC-Altitude curve is $574.6 \mathrm{~m}$ (B1) and that for HRH-Altitude curve is $1338 \mathrm{~m}$ (B2). The points of inflection for the HRC-Altitude and HRH-Altitude curves for locations spaced at $10 \mathrm{~km}$ grid were also identified. The values found with 10 and $25 \mathrm{~km}$ grids were similar, with a variation of less than $1 \%$.

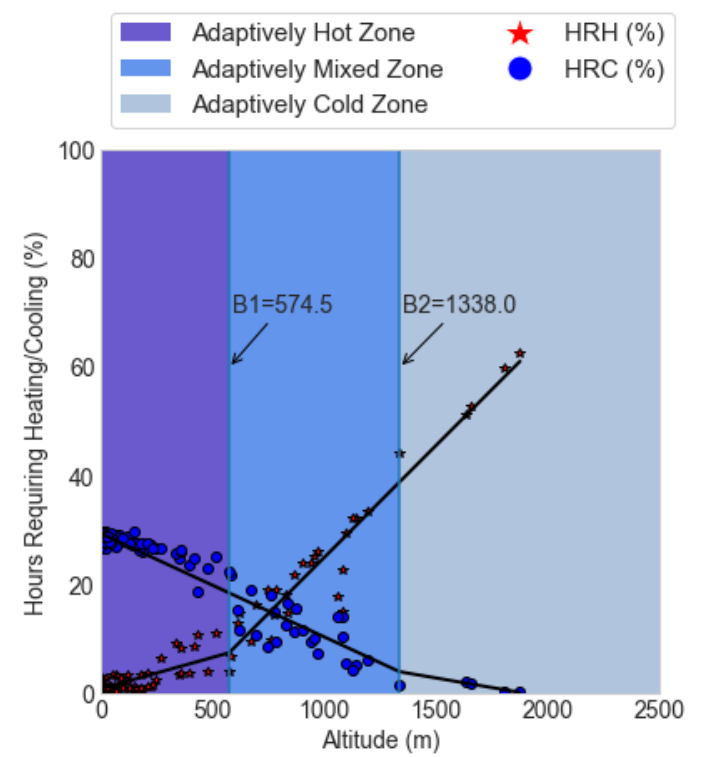

Figure 3: $H R H$ and $H R C$ at $25 \mathrm{~km}$ grid.

Thus, based on the inflection points B1 and B2, three adaptive climate zones were defined, namely:

1. Adaptively Hot Zone (AHZ): places/regions with altitudes lower than $574.6 \mathrm{~m}$ (B1).

2. Adaptively Mixed Zone (AMZ): places/regions with altitudes between $574.6 \mathrm{~m}$ (B1) and $1338 \mathrm{~m}$ (B2).

3. Adaptively Cold Zone (ACZ): places/regions with altitudes greater than $1338 \mathrm{~m}$ (B2). 


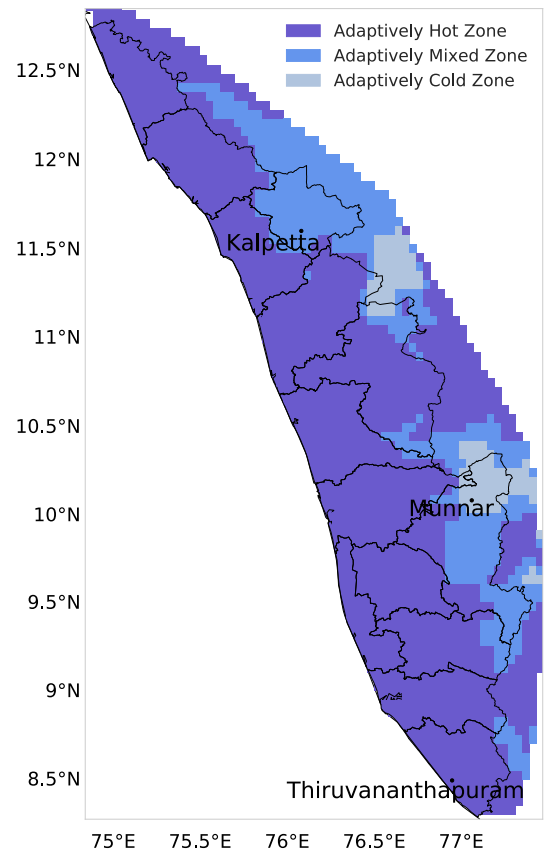

(a) Grid spacing: $10 \mathrm{~km}$.

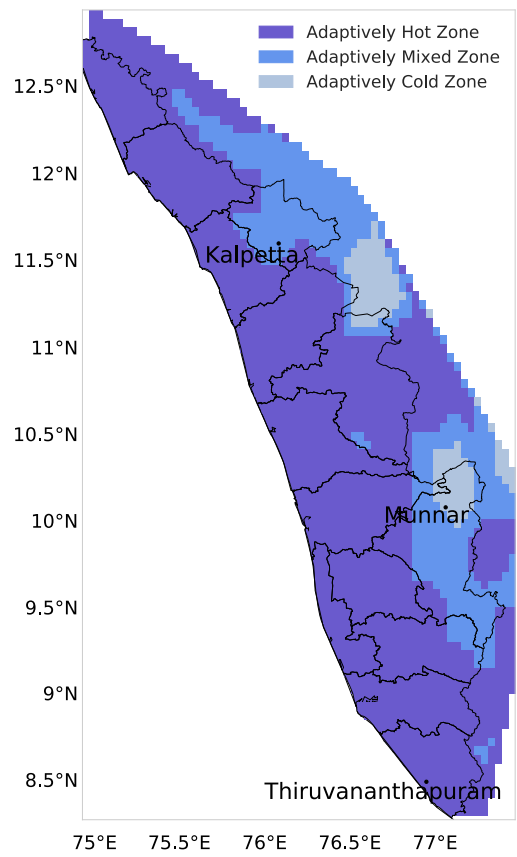

(c) Grid spacing: $20 \mathrm{~km}$.

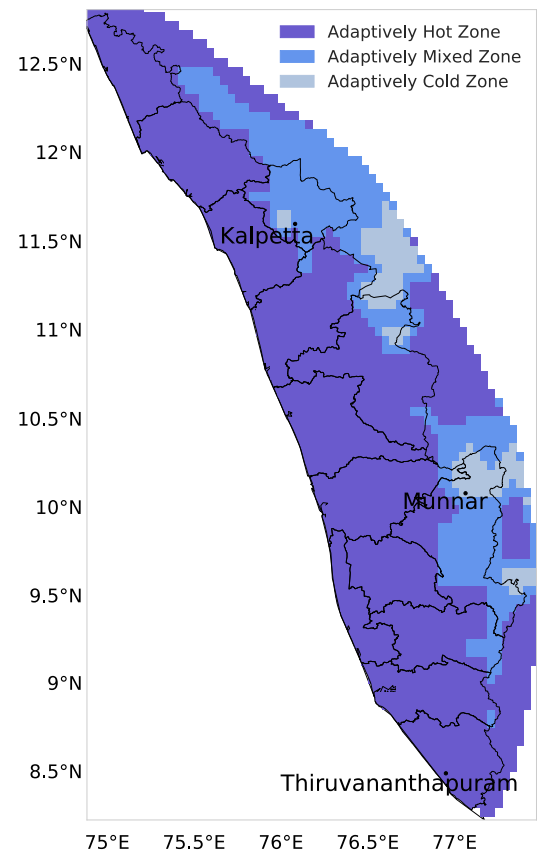

(b) Grid spacing: $15 \mathrm{~km}$.

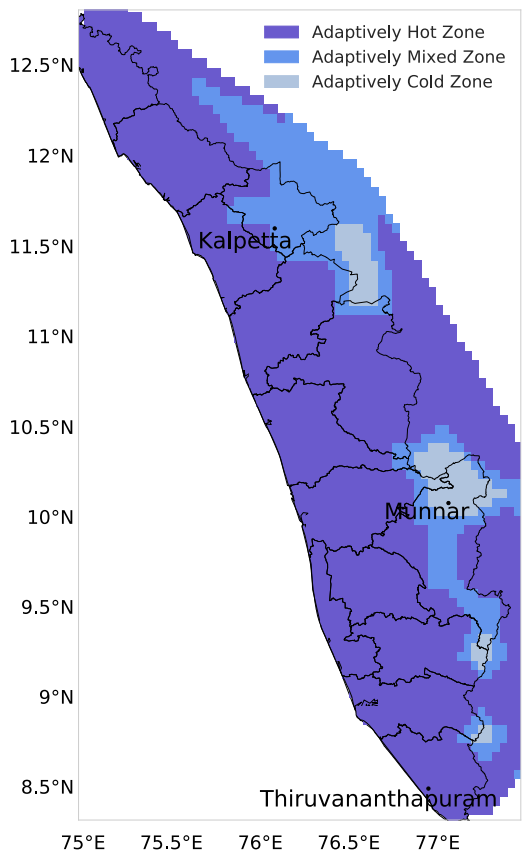

(d) Grid spacing: $25 \mathrm{~km}$.

Figure 4: Climate zones of Kerala delineated with respect to different grid spacings. For each climate zone, the location of a representative city with significant population is also marked.

\section{Climate zone delineation}

To examine the grid resolution appropriateness, the climate zones in Kerala were delineated with respect to four grid spacings: 10, 15, 20 and $25 \mathrm{~km}$. Figure 4 shows the climate zones in Kerala delineated with respect to different grid spacings.

Regions in Kerala are classified predominantly un- der climate zone AHZ. AMZ are spread towards the western side of the State. To study the appropriateness of different grid resolutions in delineating climate zones, regions surrounding three cities - Thiruvananthapuram (altitude $0 \mathrm{~m}$ ), Munnar (altitude $1532 \mathrm{~m}$ ) and Kalpetta (altitude $780 \mathrm{~m}$ ), classified under zones AHZ, ACZ and AMZ respectively, were considered. The location of these cities are marked in Figure 4. 

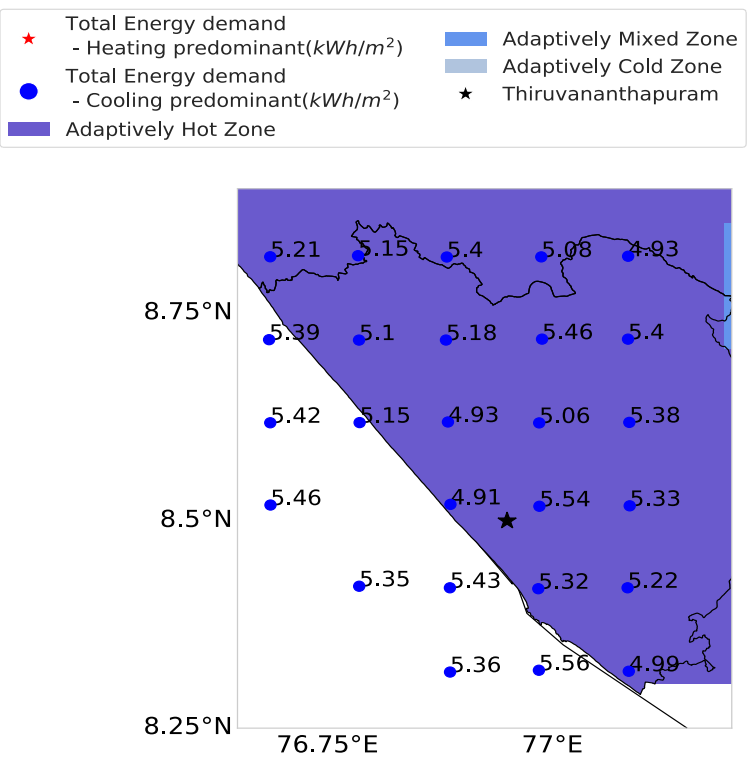

(a) Grid spacing: $10 \mathrm{~km}$.

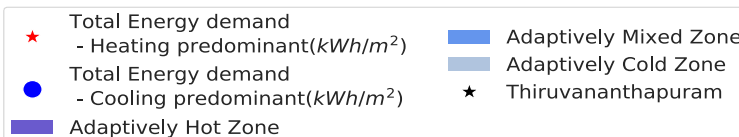

Adaptively Hot Zone

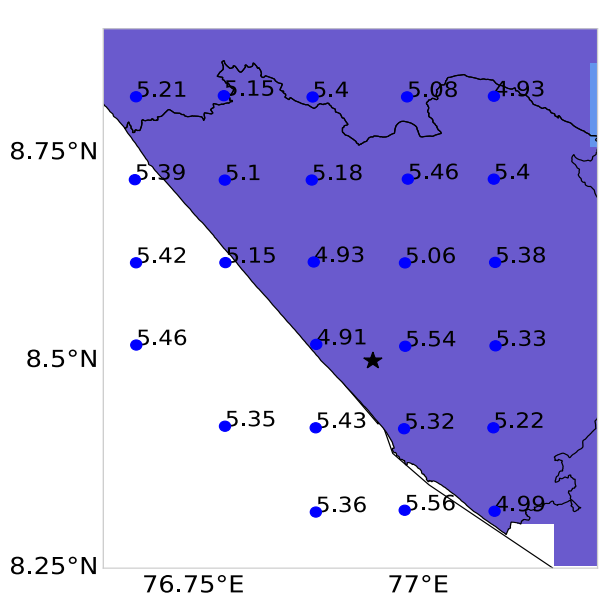

(b) Grid spacing: $15 \mathrm{~km}$.
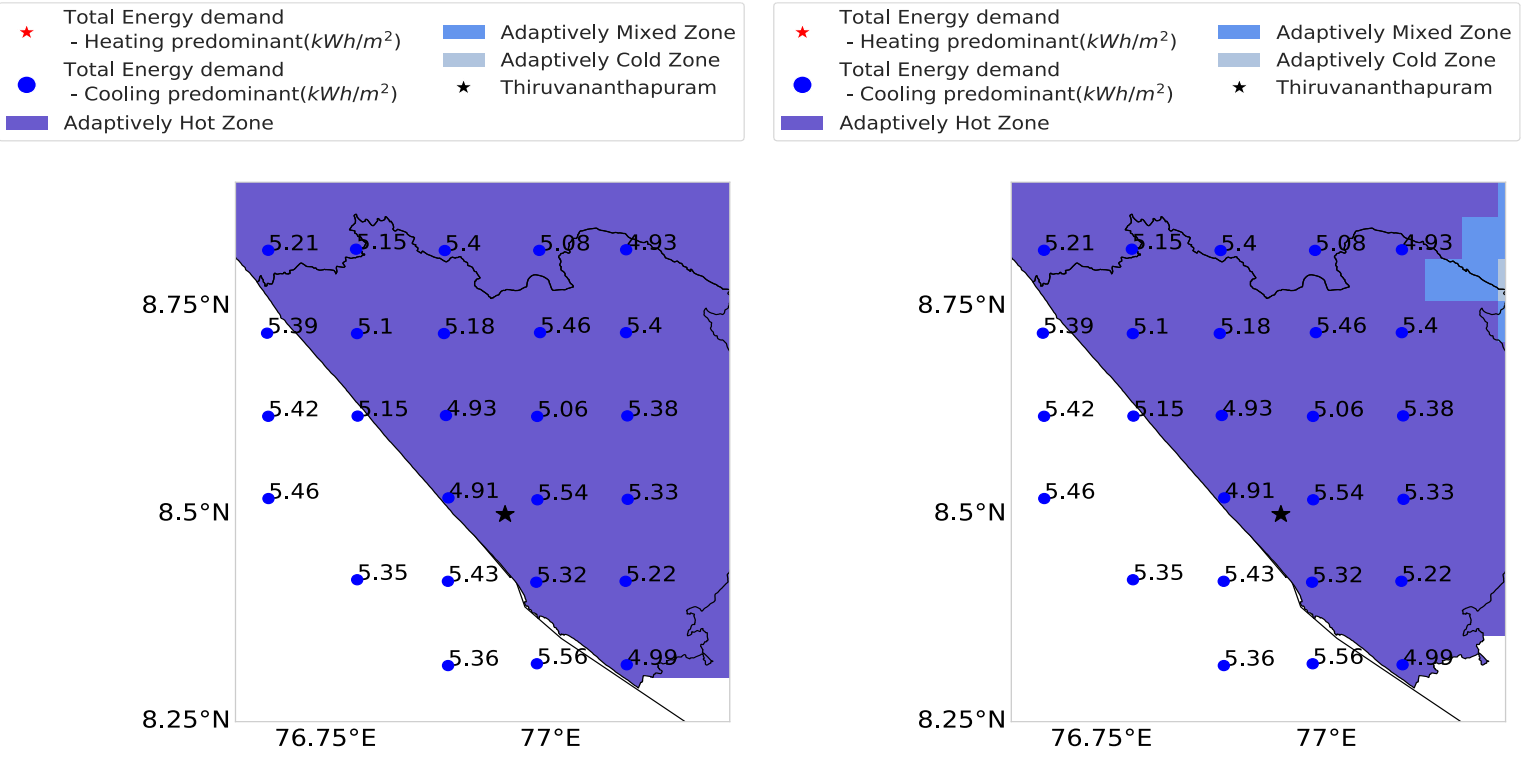

(c) Grid spacing: $20 \mathrm{~km}$.

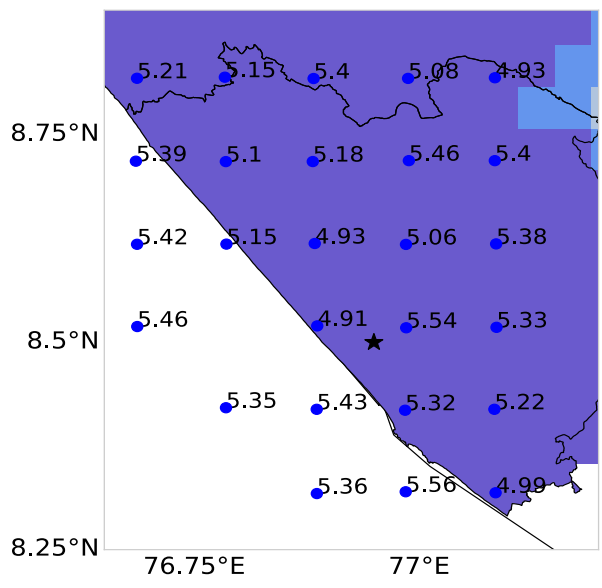

(d) Grid spacing: $25 \mathrm{~km}$.

Figure 5: Climate zones delineated around Thiruvananthapuram using data from grid spacings (a) $10 \mathrm{~km}$, (b) $15 \mathrm{~km},(\mathrm{c}) 20 \mathrm{~km}$ and (d) $25 \mathrm{~km}$. The energy demand $\left(\mathrm{kWh} / \mathrm{m}^{2}\right)$ at $10 \mathrm{~km}$ grid spacings are also marked and labelled.

\section{Climate zone delineation: region around Thiruvananthapuram}

Figure 5 shows the climate zones around Thiruvananthapuram delineated with data from different grid spacings. The total energy demand for the building located at $10 \mathrm{~km}$ grid locations are also marked.

The places around Thiruvananthapuram are classified under AHZ for all the different grid resolutions considered. The thermal performance at these locations also show similar characteristics. Thus, for places with altitudes less than $574.6 \mathrm{~m}$, a grid spac- ing of $25 \mathrm{~km}$ is appropriate.

With $25 \mathrm{~km}$ grid resolution, a relatively small region is delineated into AMZ (North East of Thiruvananthapuram in Figure 5d). This is because at $25 \mathrm{~km}$ grid, a location near the concerned zone has an altitude which is slightly above the inflection point value for the HRH-Altitude curve (i.e. $574.6 \mathrm{~m}$ ). This variability reduces at higher resolutions as seen from Figures $5 \mathrm{a}, 5 \mathrm{~b} \& 5 \mathrm{c}$. The following sections examine the grid spacing appropriateness at altitudes above $574.6 \mathrm{~m}$. 


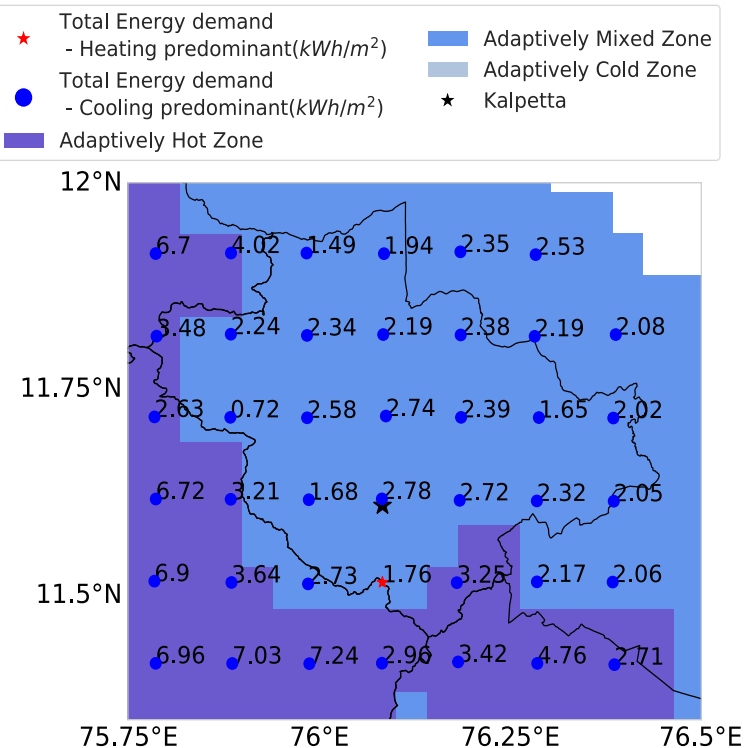

(a) Grid spacing: $10 \mathrm{~km}$.

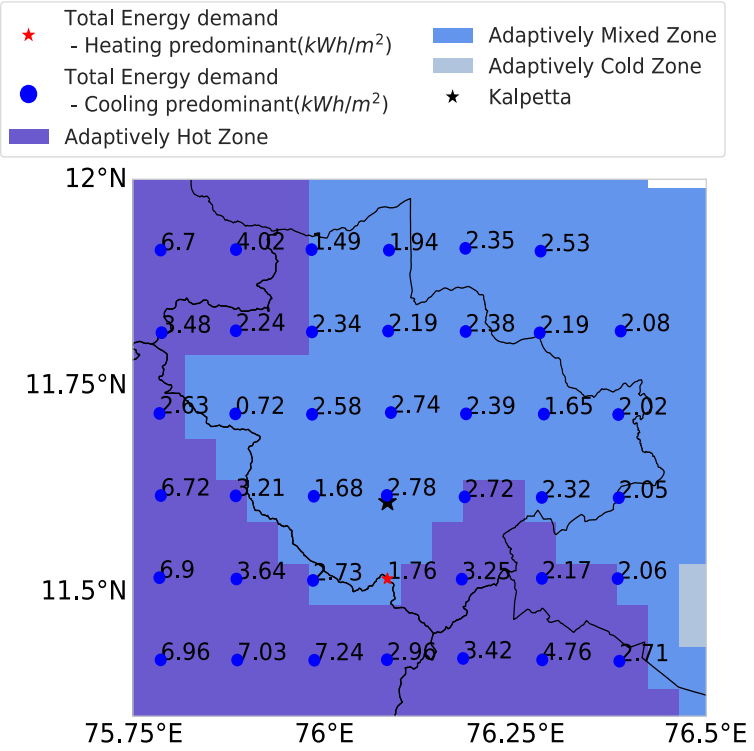

(c) Grid spacing: $20 \mathrm{~km}$.
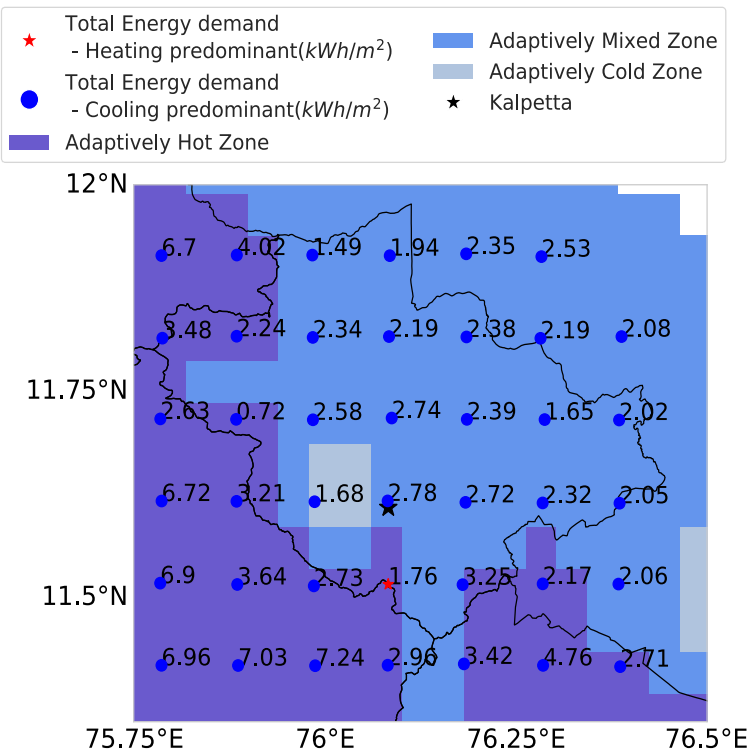

(b) Grid spacing: $15 \mathrm{~km}$.

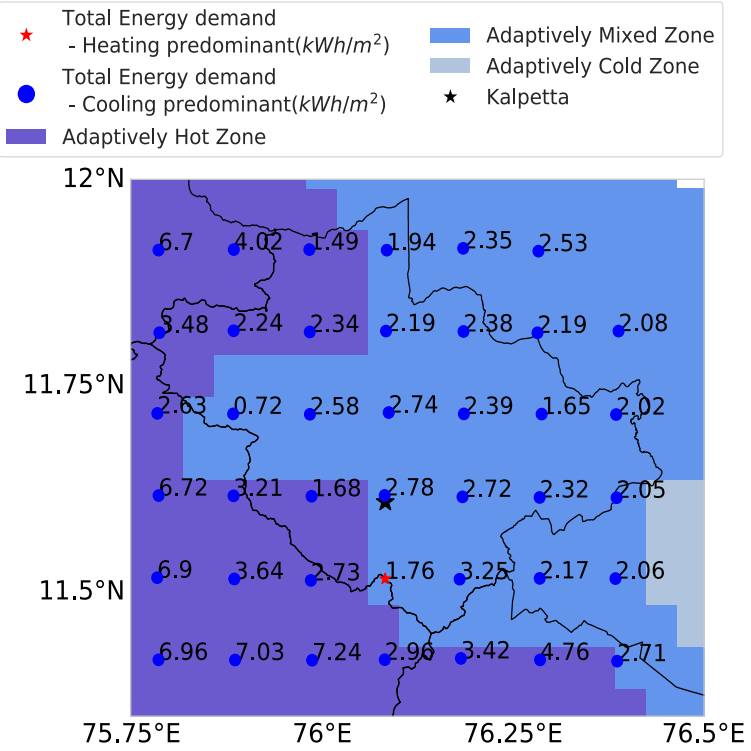

(d) Grid spacing: $25 \mathrm{~km}$.

Figure 6: Climate zones delineated around Kalpetta using data from grid spacings (a) $10 \mathrm{~km}$, (b) $15 \mathrm{~km}$, (c) $20 \mathrm{~km}$ and $(d) 25 \mathrm{~km}$. The energy demand $\left(\mathrm{kWh} / \mathrm{m}^{2}\right)$ at $10 \mathrm{~km}$ grid spacings are also marked and labelled.

\section{Climate zone delineation: region around Kalpetta}

Figure 6 shows climate zones around Kalpetta delineated with data from different grid resolutions. The region immediately around Kalpetta has an altitude between $574.6 \mathrm{~m}$ and $1338 \mathrm{~m}$. The predominant zone around the region is AMZ.

From Figures 6b, 6c and 6d places with similar thermal characteristics (Energy demands of 2.24, 2.34 and $2.19 \mathrm{kWh} / \mathrm{m}^{2}$ - located to the North/ North East of Kalpetta) are classified into different zones. Thus, for places with altitudes between $574.6 \mathrm{~m}$ and $1338 \mathrm{~m}$, higher resolution grid spacing of no more than $10 \mathrm{~km}$ is required.

In Figure $6 \mathrm{~b}$ a location with a cooling demand of $1.68 \mathrm{kWh} / \mathrm{m}^{2}$ is classified under ACZ. This is because the altitude of the concerned location is $1380 \mathrm{~m}$, which is slightly above the point of inflection for HRC-Altitude curve (i.e. $1338 \mathrm{~m}$ ). This variability, as seen earlier, is reduced at higher resolutions.

\section{Climate zone delineation: region around Munnar}

Figure 7 shows the climate zones around Munnar delineated with data from different grid resolutions. 

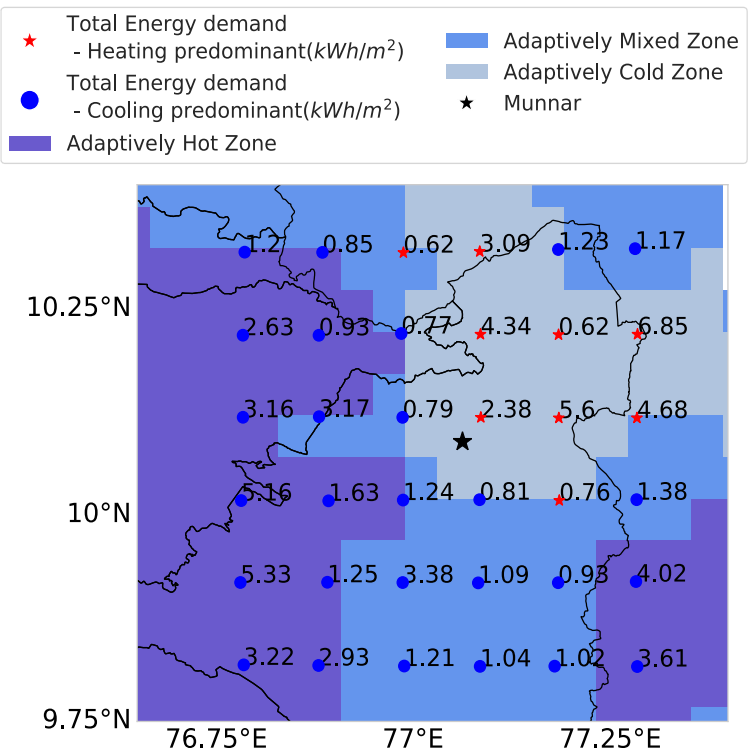

(a) Grid spacing: $10 \mathrm{~km}$.

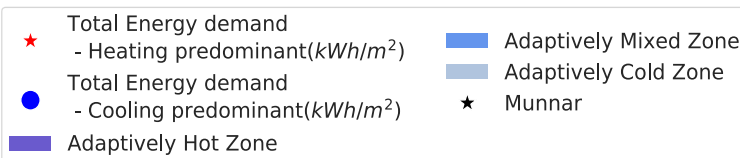

$10.25^{\circ} \mathrm{N}$

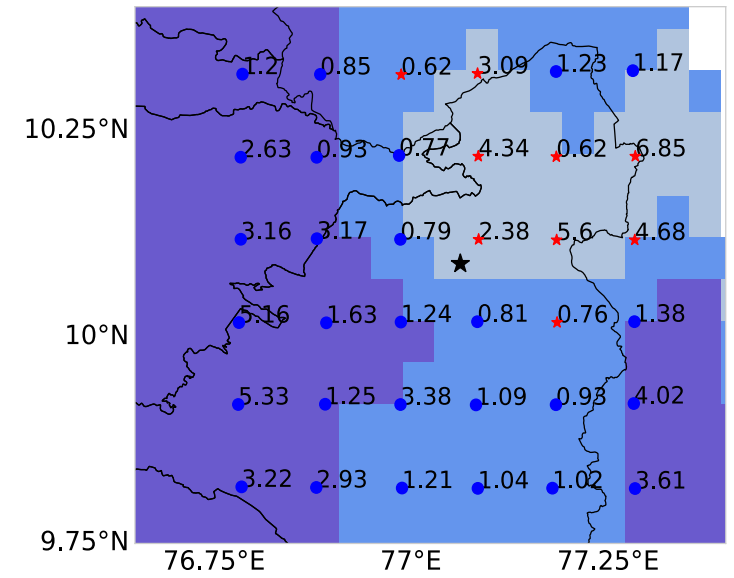

(b) Grid spacing: $15 \mathrm{~km}$.
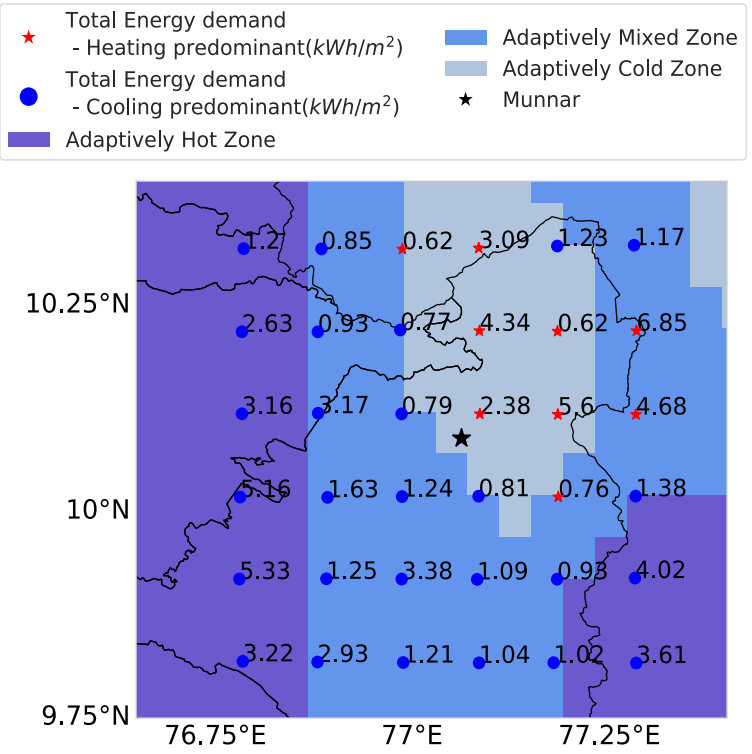

(c) Grid spacing: $20 \mathrm{~km}$

Figure 7: Climate zones delineated around Munnar using data from grid spacings (a) $10 \mathrm{~km}$, (b) $15 \mathrm{~km}$, (c) $20 \mathrm{~km}$ and (d) $25 \mathrm{~km}$. The energy demand $\left(\mathrm{kWh} / \mathrm{m}^{2}\right)$ at $10 \mathrm{~km}$ grid spacings are also marked and labelled.

The regions around Munnar show different climatic characteristics. Except under $25 \mathrm{~km}$ grid spacing (Figure $7 \mathrm{~d}$ ) all the locations under AHZ show energy demand characteristics which are predominantly due to heating demand.

Under $20 \mathrm{~km}$ grid resolution, locations with similar energy demand characteristics $\left(3.16 \mathrm{kWh} / \mathrm{m}^{2}\right.$ and $3.17 \mathrm{kWh} / \mathrm{m}^{2}$ - East of Munnar in Figure $7 \mathrm{c}$ ) are classified under two different zones. A similar observation is also made with regard to $15 \mathrm{~km}$ grid resolution. Locations with similar energy demand characteristics $\left(0.93 \mathrm{kWh} / \mathrm{m}^{2}\right.$ and $0.77 \mathrm{kWh} / \mathrm{m}^{2}$ - North
East of Munnar in Figure 7b) are classified under two different zones.

Thus, for places with altitudes greater than $1338 \mathrm{~m}$, a grid resolution of not more than $10 \mathrm{~km}$ is required.

\section{Conclusion}

The study presented in this paper investigated the grid resolution required for the classification and delineation of climate zones for energy efficient building design and performance assessment purposes. For the purpose of the investigation, climate zones in Kerala (India) were classified and delineated at grid resolu- 
tions of 10, 15, 20 and $25 \mathrm{~km}$. For the classification of climate zones, a method based on adaptive thermal comfort model was used. The appropriateness of the grid resolution for delineation was examined by comparing the variation of thermal performance of a building across different identified climatic zones.

This study identified the presence of three climate zones in Kerala which is in contrast to the observations in NBC of India and ASHRAE climate classification which delineate Kerala to be predominantly under a single climatic zone. From the findings, it was observed that for regions with altitudes lower than $574.6 \mathrm{~m}$ above sea level a grid spacing of $25 \mathrm{~km}$ is appropriate while for regions at higher altitudes, a grid resolution of not more than $10 \mathrm{~km}$ is required. Thus, the findings highlight the importance of the choice of grid resolution for classification and delineation of climate zones.

The study only considered grid resolution for climate zone classification and delineation. It is expected that at lower resolutions the point from which grids are placed may also play an important role in delineating climate zones. This will be investigated in further studies.

\section{Acknowledgment}

Mr. Jayapalan Nair acknowledges the support provided by KIIDC, Habitat Technology group and Loughborough University.

\section{References}

Ali, S., M. Sharma, and V. Maiteya (1993). Climatic classification for building design in India. Architectural Science Review 36(1), 31-34.

Bansal, N. K. and G. Minke (1995). Climatic Zones and Rural Housing in India: GermanIndian-cooperation in Scientific Research and Technological Development. Forschungszentrum Jülich GmbH, Zentralbibliothek.

Bureau of Indian Standards (2016). SP\%: National Building Code of India(NBC)-2016.

Cheng, V. and E. Ng (2006). Comfort temperatures for naturally ventilated buildings in hong kong. Architectural Science Review 49(2), 179-182.

Government of Kerala (2018, August). Kerala Post Disaster Needs Assessment - Floods and Landslides.

IEA (2015). India Energy Outlook : World Energy Outlook special report. International Energy Agency.

Ministry of Finance, Government of Kerala (2018). Budget speech 2018-2019.

Jayapalan Nair, R., E. Brembilla, C. J. Hopfe, and J. Mardaljevic (2018). Influence of climate on the daylight and thermal performance of buildings in Kerala (India). in: Proceedings of Building Simulation and Optimisation Conference. Cambridge, UK. www.ibpsa.org/proceedings/BSO2018/6B1.pdf

Manu, S., Y. Shukla, R. Rawal, L. Thomas, R. de Dear, M. Dave, and M. Vakharia (2014). Assessment of air velocity preferences and satisfaction for naturally ventilated office buildings in India. in: Proceedings of 30th International PLEA Conference Sustainable Habitat For Developing Societies Choosing The Way Forward. CEPT UNIVERSITY PRESS.

Manu, S., Y. Shukla, R. Rawal, L. E. Thomas, and R. de Dear (2016). Field studies of thermal comfort across multiple climate zones for the subcontinent: India Model for Adaptive Comfort (IMAC). Building and Environment 98, 55-70.

Marsh, L. C. and D. R. Cormier (2001). Spline regression models, Volume 137. Sage.

Nicol, J. (1974). An analysis of some observations of thermal comfort in Roorkee, India and Baghdad, Iraq. Annals of human biology 1(4), 411-426.

Pawar, A. S., M. Mukherjee, and R. Shankar (2015). Thermal comfort design zone delineation for India using GIS. Building and Environment 87, 193-206.

Meteotest, Switzerland (2014). Meteonorm global meteorological database-Handbook Part II: Theory, Version \%.1.

Singh, M. K., S. Mahapatra, and S. Atreya (2007). Development of bio-climatic zones in North-East India. Energy and buildings 39(12), 1250-1257.

Standard 169 (2013). Climatic data for building design standards. ASHRAE Standard 169-2013.

Standard 55 (2013). Thermal environmental conditions for human occupancy. ASHRAE Standard 55-2013.

van Ruijven, B. J., D. P. van Vuuren, B. J. M. de Vries, M. Isaac, J. P. van der Sluijs, P. L. Lucas, and P. Balachandra (2011). Model projections for household energy use in India. Energy Policy 39, 7747-7761.

Walsh, A., D. Cóstola, and L. C. Labaki (2017). Review of methods for climatic zoning for building energy efficiency programs. Building and Environment 112, 337-350. 